\title{
LUNG CARCINOMA IN YOUNG ADULT MALES
}

\author{
T. Dhanasekar1' P. M. Anbumaran², B. Rajagopalan³, Shanmugapriya K4
}

\section{HOW TO CITE THIS ARTICLE:}

T. Dhanasekar, P. M. Anbumaran, B. Rajagopalan, Shanmugapriya K. "Lung Carcinoma in Young Adult Males". Journal of Evolution of Medical and Dental Sciences 2015; Vol. 4, Issue 36, May 04; Page: 6346-6349, DOI: $10.14260 /$ jemds/2015/922

\begin{abstract}
Here we report three case of Lung Carcinoma in young adult males, non-smokers, no family history of malignancy and no other risk factors like occupational or environmental exposure, past history of tuberculosis or chronic obstructive bronchitis, who presented with variable chest radiographic and computerized tomographic findings, these cases warrants further analysis regarding the changing trend of higher incidents of lung carcinoma in young adult males.
\end{abstract}

KEYWORDS: Adeno Carcinoma, PET Scan, Ewing's Sarcoma

INTRODUCTION: Lung Cancer is a leading cause of cancer deaths in developed countries and is also raising at alarming rates in developing countries. This is the single most devastating cause of cancer related deaths with approximately 1.5 million cases worldwide. Lung cancer is responsible for about 1 million deaths per year at present and it will rise to three million per year by the year of 2010 . Young patients are very likely to be symptomatic present with advance disease. There is changing trend of higher incidence of Lung carcinoma in young patients. In addition to smoking, occupational exposure to carcinogens, indoor air pollution, dietary factors and family history of cancer have recently being implicated in causation of Lung cancer. We report three cases of lung carcinoma in young adult males in absence of any known etiological risk factors.

\section{CASE REPORT:}

CASE 1: An 32 years old male, call center worker by occupation came with complaints of dry cough for two weeks, acute in onset, progressive in nature, not associated with expectoration, increased on deep inspiration, decreased on lying on left lateral position. History of increased shortness of breath for ten days not associated with wheeze, grade 3 MMRC. History of orthopnea present. No history of PND. History of hoarseness of voice for five days. He was a non-smoker and had no significant past medical or family history. There was no history of occupational or environmental exposure.

On examination, the patient was moderately built and nourished, with pallor on general physical examination. Systemic examination revealed shift of trachea to the right. On auscultation, normal vesicular breath sounds were heard on right side of chest. Whereas breath sounds were absent on left side. Investigation revealed hemoglobin $9.4 \mathrm{~g} / \mathrm{dl}$ with normal differential and total leucocyte count. Chest radiograph showed an opaque hemithorax on the left side with right shifting of trachea and mediastinun. Computerized tomography scan of the chest suggested of massive left sided pleural effusion with complete collapse of the left lung with numerous enhancing lobulated nodules in the left pleura. Patient underwent left sided thoracentesis, pleural fluid cytology suggestive of polymorphous cellular infiltrates with atypical cells. CT guided biopsy of the left pleural based mass showed features of ADENOCARCINOMA. Patient expired within a week of diagnosis. Atopsy was refused by the relatives. 


\section{CASE REPORT}

Opaque Hemithorax on the left side with right shifting of trachea and mediastinum.

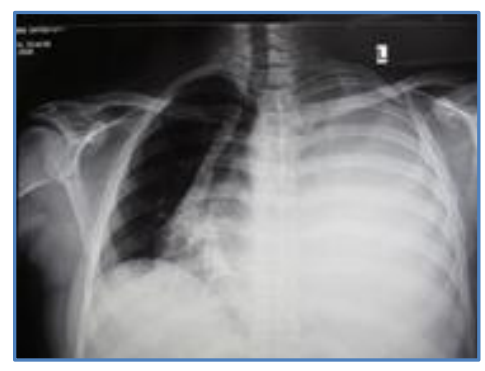

Fig. 1

Massive Left sided pleural effusion with complete collapse of left lung with numerous enhancing lobulated nodules in the left pleura.

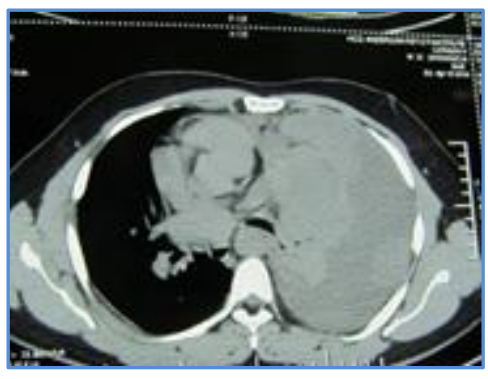

\section{Fig. 2}

CASE 2: An 24 years old male came with complaints of increased shortness of breath and loss of weight for 2 months. He was a non smoker and had no significant past medical and family history. On examination patient was thin built, clubbing grade 1 present with multiple cervical lymphnodes were palpable. On auscultation, there was decreased breath sounds over the right infraclavicular and mammary region. Chest radiography showed non homogenous opacities on the right upper zone with mediastinal widening. FNAC of cervical lymphnode showed positive for malignancy showing clusters of atypicil cells. CT guided biopsy showed features suggestive of small cell carcinoma.

Chest x-ray showed non-homogenous opacities on the right upper zone with mediastinal widening.

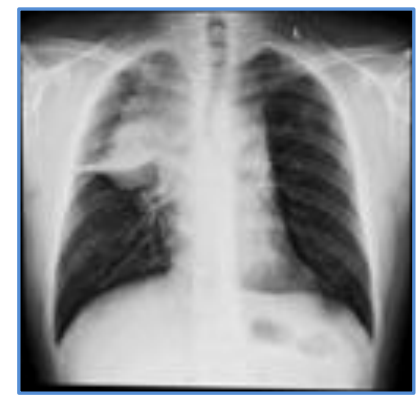

\section{Fig. 3}

Picture showing CT guided biopsy of right upper zone mass. 


\section{CASE REPORT}

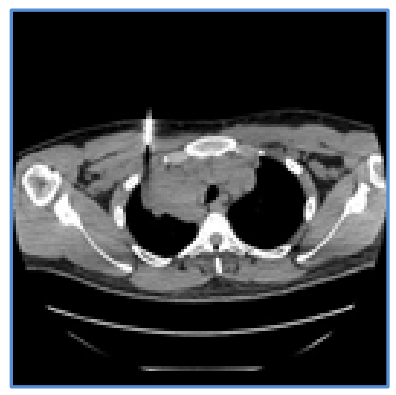

Fig. 4

CASE 3: An 15 year old male came with complaints of fever and left sided pleuritic chest pain and shortness of breath for 3 days. On examination trail's sign was present on the right side with absence of breath sounds on the left infrascapular and infraxillary region an auscultation. Chest x-ray showed left moderate pleural effusion CT and PET Scan reports suggestive of aggressive heterogeneously enhancing soft tissue mass lesion in the superior basal segment of left lower low with chest wall invasion. CT guided biopsy reports suggestive of EWING'S SARCOMA.

Homogenous opacity over the left lower zone.

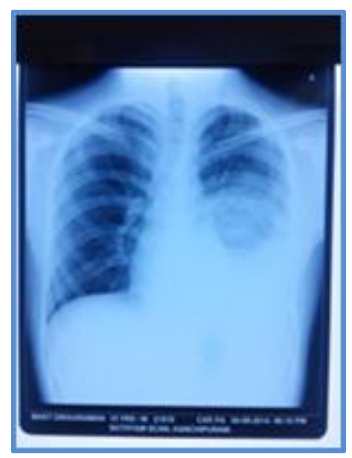

\section{Fig. 5}

Heterogeneously enhancing soft tissue mass lesson in the superior basal segment of left lower lobe with chest wall invasion.

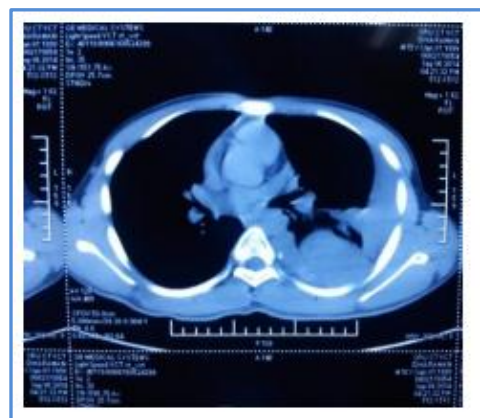

Fig. 6

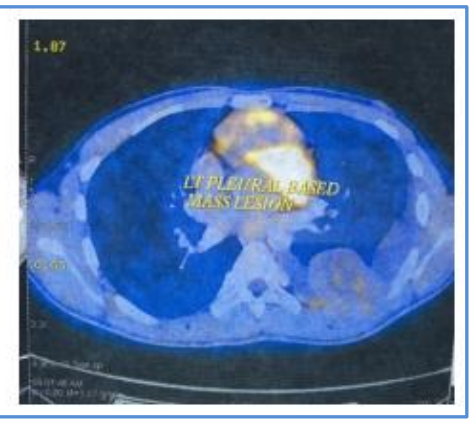

Fig. 7

DISCUSSION: W. Bourke et al in his study he quoted in isreal younger patients more frequently presented with stage 1 disease and they had higher incidence of adeno carcinoma.[1] Alexander Kennedy et al studies 40 cases in which the diagnosis of lung cancer was established histologically 
before the age of 40 years Chih - Wei Kuo et al compared Non -small cell Lung cancer in very young and very old patient.[2] He reported that younger patient were more frequently to be found at an advanced disease status with a poor prognosis. Guntuly AK et al compared the epidemiology, clinical of laboratory characteristics of survival rates of younger and older patient's lung cancer. They studied 1340 patients who were histopathologically diagnosed as having Lung cancer from 1990 to 2005 of the 1340 patients, 179 (13.4\%) were in the young group.[3] Larsen KR et al reviewed by series of younger patient with primary Lung cancer patient below 40 years of age represent between 1.2 \& $5 \%$ of total Lung cancer population.[4] Rocha MP et al Reviewed the cancer registry files of the Ben Taub General Hospital (Houston, TX) from 1971 to 1989 and identified 1678 patients with a documented diagnosis of Lung cancer. Among these 1678 patients, 50 were age 40 or less. 27 patients had adenocarcinoma, Eight had squamous cell carcinoma and six had other non-descript, non-small cell carcinoma types.[5]

\section{REFERENCES:}

1. W. Bourke; D. Milstein ; R. Giura; M. Donghi; M. Linsetti; A. H. Rubin ; L. J. Smith Chest. 1992; 102 (6): 1723 - 1729, dol.10.1378/chest, 102.6.1723.

2. Chih-wei kuo.MD; Yuh-min chen. MD, PH.D, FCCP; Jing - Yi Chao, MPH, MSW, et al ; Non-small cell lung cancer in very young and very old patients. Chest. 2001; 117(2): 354-357, doi: 10.1378/Chest. 117.2.354.

3. Guntulu AK, Muzaffer Metintas, Husey in yildirim, Sinan Erginel, Fusun Alatas: Lung cancer in Individuals less than 50 years of age. Lung September 2007, 185(5):279 - 286.

4. Larsen K R, Grode G W, Olsen $0 \mathrm{~T}$ (primary lung cancer in patients under 40 years of age). Ugester Laeger. 1994 May 16; 156(20):3018-21. PMID 8023407 [pubmed].

5. Rocha MP, Fraire AE, Guntupalli KK, Greenberg SD: Lung cancer in the young cancer Detect prev 1994:18(5): 349-55. PMID: 7812981 [pubmed].

\section{AUTHORS:}

1. T. Dhanasekar

2. P. M. Anbumaran

3. B. Rajagopalan

4. Shanmugapriya K.

\section{PARTICULARS OF CONTRIBUTORS:}

1. Associate Professor, Department of Pulmonary Medicine, Sri Ramachandra University, Chennai, India.

2. Post Graduate, Department of Pulmonary Medicine, Sri Ramachandra University, Chennai, India.

3. Professor \& HOD, Department of Pulmonary Medicine, Sri Ramachandra University, Chennai, India.

FINANCIAL OR OTHER COMPETING INTERESTS: None
4. Post Graduate, Department of Pulmonary Medicine, Sri Ramachandra University, Chennai, India.

\section{NAME ADDRESS EMAIL ID OF THE CORRESPONDING AUTHOR:}

Dr. T. Dhanasekar, \# AJ-147, No. 3, Golden Aster Apartments, $9^{\text {th }}$ Main Road, Anna Nagar, Chennai-600400.

E-mail: drdhanasekar@yahoo.com

Date of Submission: 10/04/2015.

Date of Peer Review: 11/04/2015.

Date of Acceptance: 24/04/2015.

Date of Publishing: 04/05/2015. 